\title{
FORUM
}

\section{The Measurement of Range and Velocity of Approach during the Berthing of Tankers}

\author{
R. N. B. Gatehouse
}

A ReQuirement was stated to Brookes \& Gatehouse Ltd. by B.P. Ltd. in 1962 for the measurement of velocity of approach, at the instant of impact against the fenders, of large tankers when berthing at a jetty. This information was required for operational research into the design of jetties for the new super-tankers and for 'post-mortems' after heavy impact. Experiments were carried out by us at the Fawley terminal of the Esso Company and the first installation was made by B.P. at their Finnart terminal in January 1963 . There has been a continuing demand up to the present time by several oil companies, and a dozen jetties in different parts of the world have now been fitted with this equipment.

The principle of operation is to employ a slightly modified version of the 'Hecta' ultrasonic echo-sounder, the transducer beam being directed horizontally through the water and in a direction perpendicular to the wall from a fixed position on the structure of the jetty (Fig. I). Echoes are obtained from the immersed vertical side of the ship. The output of this sounder is in the form of a direct current proportional to the range of the echoing object. The d.c. signal is fed into a recording milliammeter, the chart of which runs at a known constant speed, and the slope of the resulting curve at any desired instant is measured in order to derive the velocity of approach. The echo-sounder and recorder are installed in the docking control office.

Generally two echo-sounders and a dual-trace recorder are installed, the transducers being so located as to give readings at points close to the bow and stern. The rate of yaw during approach and the obliquity at any instant can thus also be determined.

A typical trace from one of the pair of recorders during a berthing operation at Milford Haven is reproduced as Fig. 2. The recording commences at a range of $50 \mathrm{ft}$. and impact occurs at point $B$ about three minutes later. Line OP is drawn tangential to the curve at $B$ and the slope, which is $P Q / O Q$, is calculated. This gave an impact velocity of $13.3 \mathrm{ft} / \mathrm{min}$. (Scale of chart is $5 \mathrm{ft} / \mathrm{div}$. and $5 \mathrm{sec} /$ div.) After impact the fenders deflect and then run out to their normal position at point $C$. It is seen that in this case the fender deflection amounted to $2 \mathrm{ft}$.

Since the minimum range of an echo-sounder is finite, in this case $2.5 \mathrm{ft}$., the transducer has to be installed at a distance no less than this value from the point of closest approach of the side of the vessel. If the tidal range exceeds the draft of the lightest vessel upon which measurements are required to be made, it becomes necessary to install two transducers at each measuring point, as 
shown in the inset to Fig. 1. A switch, which may be automatically operated, selects the pair of transducers appropriate to the existing tidal height.

The maximum range at which measurements are possible with a laden tanker and using existing designs of equipment is about $200 \mathrm{ft}$. So far no use has been made of soundings greater than $50 \mathrm{ft}$. since the main requirement is to determine velocity with the greatest possible accuracy during the final phase of the berthing operation.

It would not seem to be impracticable, however, to re-design the equipment
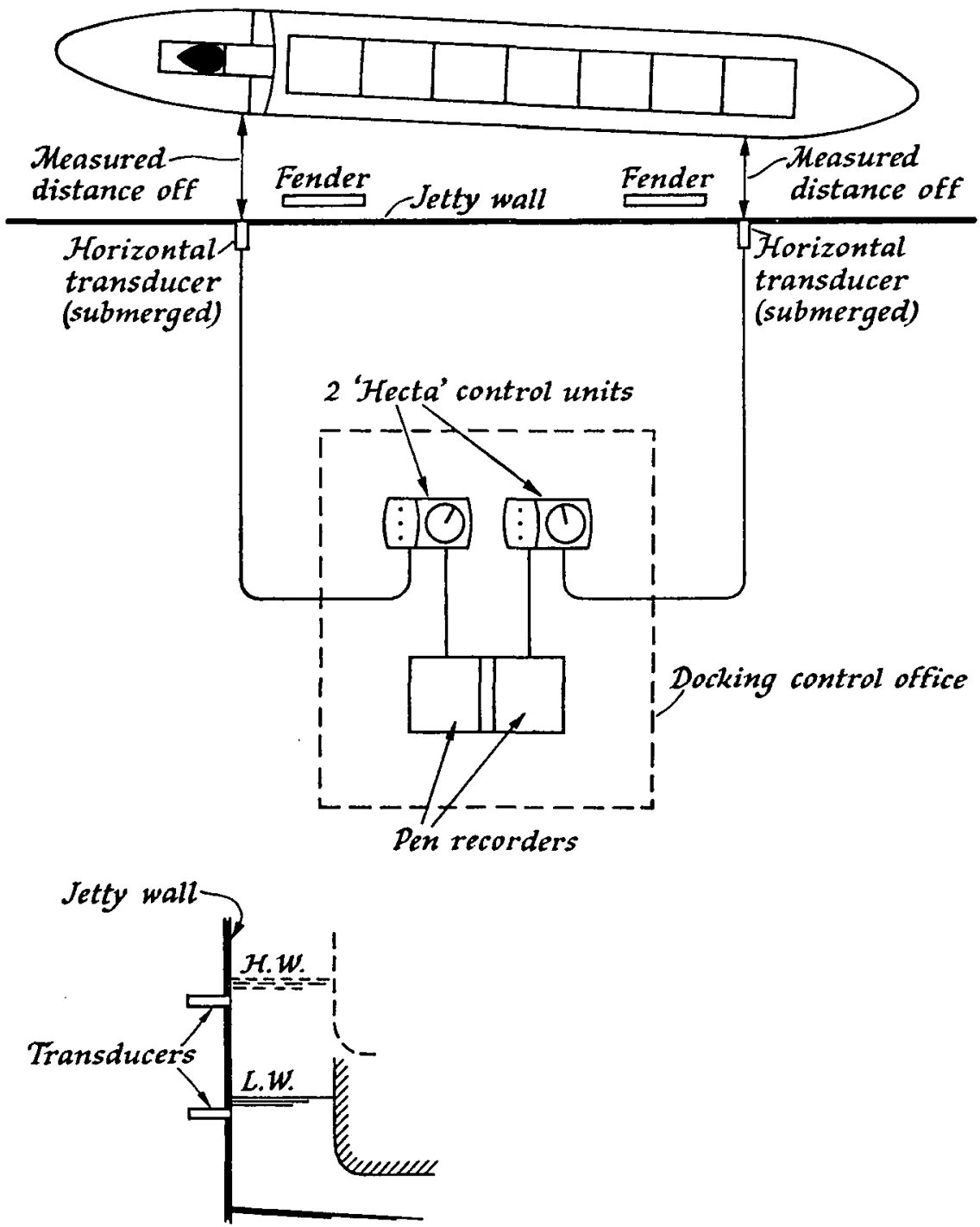

2-tier transducer arrangement

for extensive tidal range

FIG. I. General arrangement of the echo-ranging system 
in such a way that it could provide both range and velocity data continuously at distances up to $400 \mathrm{ft}$. These could be sent by radio telemetry to the ship, where they could be displayed on dials mounted in a portable receiver which is carried by the pilot. An audible warning device could be fitted in the receiver

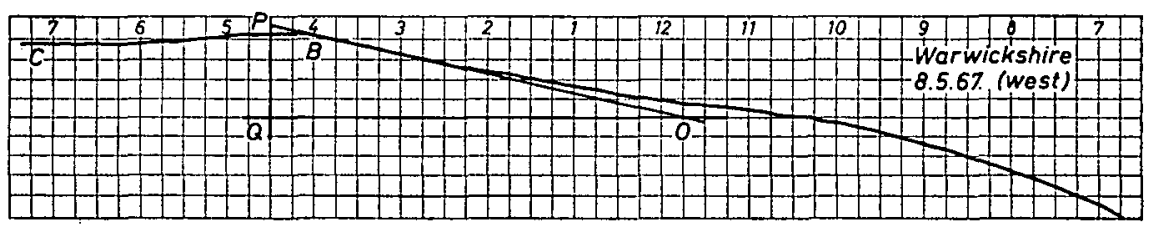

FIG. 2. Typical tracing during the berthing operation

which would operate whenever the velocity of approach exceeds the maximum safe value.

A brief summary of the characteristics of the 'Hecta' is as follows:

Ranging accuracy: 3 per cent of range or 6 in., whichever is the greater. Power consumption : $100 \mathrm{~mW}$. from internal mercury cells.

Display: Meter of $2 \mathrm{~mA}$. sensitivity for F.S.D., together with recorder. The two instruments are series-connected.

Weight of instrument case : $4.5 \mathrm{lb}$.

Ultrasonic carrier frequency: $177 \mathrm{kHz}$.

Transducer beam width between the $-6 \mathrm{~dB}$. points : $25^{\circ}$.

The type of recorder in most general use in the berthing application uses pressure-sensitive paper and has a chart width of 21 in. The chart runs at a speed of 3 in. per minute.

\title{
Rhumb-line Failings
}

\author{
J. S. McKenzie \\ (Marine \& General Computer Consultancy (I.O.M.) Ltd.)
}

TURNER has chosen in a recent paper 1 to criticize Moss 2 for inaccurate methods and observes that the inherent inconsistencies are 'educationally objectionable'. However, he who criticizes must be prepared to be criticized in turn, and when a computer program of the standard evidenced in the printout of PROGRAM 2 is put forward as a general solution to the rhumb-line problem, and one which will enable the navigator to compute his tracks rapidly and accurately, we must needs examine it closely. Such an examination shows that, at the very least, the programmed solution offered is 'computerizationally objectionable'.

Throughout his paper Turner seems to infer that the computer is a panacea and non-technical readers are presumably expected to express awe when told 